Jurnal Pena Sains Vol. 5, No. 1, April 2018

\title{
INVESTIGATION OF THE MISCONCEPTION IN NEWTON II LAW
}

\author{
Yudi Kurniawan ${ }^{1}$ \\ ${ }^{1}$ STKIP Singkawang \\ Singkawang, 79251, Indonesia \\ yudikurniawan1012@gmail.com
}

\begin{abstract}
This study aims to provide a comprehensive description of the level of quantity of students who have misconceptions about Newton's II Law. This research is located at one State Junior High School in Kab. Pandeglang. The purposive sampling was considering used in this study because it is important to distinguish students who do not know the concept with students who experience misconception. Data were collected using a three tier-test diagnostic test and analyzed descriptive quantitatively. The results showed that the level of misconception was in the two categories of high and medium levels. It needs an innovative teaching technique for subsequent research to treat Newton's Newton misconception.
\end{abstract}

Keywords: Investigation, Levels, Misconception, Newton's Newton II Law 


\section{Introduction}

The misconception may occur due to the presence of misinterpretation of natural phenomena or processes that are interconnected. Relationships between concepts are believed by someone different from the conception expressed by the experts (Muliyani \& Kaniawati, 2015).

Even at some of the related misconception to study, it was found that misconceptions are resistant even to the same misconception revealed repeatedly. This state indicates that the existence of differences in learning objectives that set the systemic (curriculum) so that the focus of teaching in the classroom is the achievement of learning outcomes is not about diagnosing the misconception (Halim, Yong, Subahan, \& Meerah, 2014). In addition, the process of learning and teaching in the class necessarily become the media occurrence of behavior changes that don't know be know so that new knowledge (General learning aims at transferring the knowledge) or precisely triggers the onset of misconceptions. Even so, it does not mean ignore the importance of learning (Samsudin, Liliawati, Dedy, Suhendi, \& Kaniawati, 2014).

Fundamental physics Concepts which are common misconceptions include the law of Newton's II. This concept is the application of the concept of mechanics is the most widely encountered in Physics problems in high school. Misconceptions about Newton's Laws are also found with different level of education and a wide age range. Thus, these concepts play an important role in learning physics (Fadaei \& Mora, 2015).

An important first step to address the misconception of Newton II law is to diagnose what kind of misconception and level the misconception. Therefore, this study aims to get an overview of the number of students that misconception on the laws of Newton's II and how the level of misconception. This research is usedl as a database related research against early misconception (dynamics of Newton's Laws) to be the next research data.

\section{Research Methods}

This research is quantitative descriptive research. Research on one of the junior high school in Pandeglang is done to get a clear misconception forms of Newton II law. Respondents involved in this study were selected by purposive sampling. This sampling technique is used to distinguish a student who was popular with students who do not know the concept though he has studied Newton's Law.

The sampling technique is excellent for analyzing the answers wrong misconceptions and wrong answer that did not yet study the resulting legal concepts of Newton II law. If students who haven't studied Newton II law tested his ability the concept then the most logical decision for students who choose the wrong answer is not known, not a misconception. That is because the selected sample has not yet been completely studied Newton II law. Hence, the ambiguity over the student's answer is wrong (whether popular or not) can be avoided in this research.

The instrument used in this research is the diagnostic test three-tier test. This test has been measured and calculated coefficients of reliabilities using the testretest. The result of this instrument worthy of use.

To determine the decision in determining the student's answers in answering test items, researchers take into account all aspects of the three-tier test. 
The decision to answer the wrong students are classified as a misconception or does not refer to decisions made by Muliyani \& Kaniawati (2015) as follows.

Table 1. The decision of the three-tiered test

\begin{tabular}{|c|c|c|c|}
\hline tier-1 & tier-2 & $\begin{array}{c}\text { tier- } \\
3\end{array}$ & Decision \\
\hline true & true & Sure & $\begin{array}{l}\text { The conception is } \\
\text { true }\end{array}$ \\
\hline true & true & $\begin{array}{l}\text { not } \\
\text { sure }\end{array}$ & Lucky guess \\
\hline true & wrong & sure & Misconception \\
\hline true & wrong & $\begin{array}{l}\text { not } \\
\text { sure }\end{array}$ & Guess \\
\hline wrong & wrong & sure & Misconception \\
\hline wrong & wrong & $\begin{array}{l}\text { not } \\
\text { sure }\end{array}$ & Lack of Knowledge \\
\hline wrong & true & sure & Misconception \\
\hline wrong & true & $\begin{array}{l}\text { not } \\
\text { sure }\end{array}$ & Guess \\
\hline
\end{tabular}

(Muliyani \& Kaniawati, 2015)

Once retrieved data distribution on the distribution of students that misconception what is found, then the next stage is to determine the criterion level the misconception that occurs in the sample. Therefore, in determining the level of the misconception that is owned by the respondent/sample than used the criteria designed by Kurniawan \& Suhandi (2015) as in table 2.

Table 2. The Criteria Of Misconception

\begin{tabular}{ccl}
\hline No & \multicolumn{1}{c}{ Percentage $(\%)$} & Criteria \\
\hline 1 & $0<$ misconception $\leq 30$ & Low \\
2 & $30<$ misconception $\leq 70$ & Medium \\
3 & $70<$ misconception $\leq 100$ & High \\
\hline
\end{tabular}

(Kurniawan \& Suhandi, 2015)

The data have been obtained were analyzed to quantify the percentage of misconception and compared with the criteria in table 2 .

\section{Result and Discussion}

After processing the data of the research results, the findings obtained some form of popular distributions of percentage are served later in figure 1 . As for the form of statement of misconception that retrieved: 1) a moving Object due to the cast tends to keep it moving because a given hand-throw style to move objects, still working on that thing; 2) when the two objects different mass is dropped from the same height then the mass of the larger object would be first up on the floor compared to the mass of the smaller object; 3 Movable Objects) because the number of the forces acting on that object is proportional to its velocity; 4) friction occurs only between two objects that are the rough surface; and 5) motion of the object is always the same as the direction of the force acting on it.

This misconception to data obtained from the analysis of the student's answer options in the recapitulation fills three tier-test both at tier-1, tier-2 or an option the reason intentionally left blank by the researchers so that able to crawl/detect new forms of misconception or new form editor in cognitive misconceptions students.

Researchers try to dig deeper by asking questions at a glance to some students that the answers to the threetiered test contain the entirety of the Mis1 to Mis-5. Entirely (though with a different editor) emphasized over experience going through every day to translate their idea into a phenomenon was shown in the classroom.

Furthermore, the results data analysis answers the whole students (in answering the three tier-test) which has 
been ascertained misconception calculated and presented in the form of diagrams with different value percentage. Figure 1 shows a comparison of the percentage of each misconception in Newton II law.

Tab Table 3 shows the students answer analysis recapitulation they have misconceptions.

Table 3. Misconception Recapitulation

\begin{tabular}{lcc}
\hline No-Mis & $\begin{array}{l}\text { Number } \\
\text { students }\end{array}$ & of \\
\hline Mis-1 & 51 \\
Mis-2 & 45 \\
Mis-3 & 50 \\
Mis-4 & 36 \\
Mis-5 & 43 \\
\hline
\end{tabular}

If the data in table 3 is examined by considering the overall number of students involved (62 students), then the data can be presented in percentages such as Figure 1. For instance, the structure of diagnostic instruments, three-tiered test to reduce misconceptions (on the example of Mis Mis-1 and-2).

(Mis-1).

A moving object due to the cast tends to keep it moving because a given handthrow style to move objects, still working on that thing.

Problem:
An object (mass $=0.1 \mathrm{~kg}$ ) thrown vertically
upwards. When an object is being floated in
the air (being up), styles are working on that
thing? Hint: air friction is negligible.
a. The force of gravity and roll Style
b. Throw Style
c. The force of gravity *
The reason choosing answers:
a. Because of the style of throw (by hand)
that is given to objects, just to give you
an initial velocity on objects, then when
the object is being floated in the air (no
hand contact with objects) then the

styles that affect the objects by the gravitational force of the Earth the direction opposite to the direction of motion of the object*

b. Because a given Throw style continued to work on it as long as it is still moving and pulled by the gravity of the Earth then the forces acting on an object is the force of Earth's gravity and style roll

c. Because objects can move up due to a Cannonball is given on objects, then for a fixed object moves up to the top, the forces acting on the object is the force roll because the difference is greater than the gravitational force

d. $\quad \ldots$

\section{Belief choices:}

a. sure * b. not sure

\section{(Mis-2).}

When two objects of different mass are dropped from the same height then the mass of the larger object would be first up on the floor compared to the mass of the smaller object.

\section{Problem:}

Note the two objects in the picture!

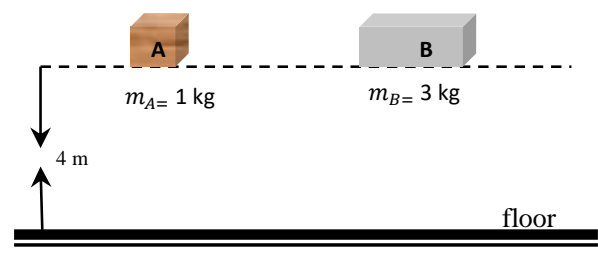

An object made of wood whereas the B objects are made of iron. Suppose both objects were dropped simultaneously and air resistance is negligible. Where is the first to beam to the floor?

a. Beam B first reach the floor

b. A Beam before it reaches the floor

c. Beams A and B beams arrive on the floor at the same time*

\section{The reason choosing answers:}

a. The speed of the falling object is independent of mass* 


b. Free falling objects Velocity
proportional to the gravity of the style.
The greater mass will experience a
greater style, so first up to the floor
c. The speed of the falling object is
proportional to its acceleration. A
smaller mass will experience greater
acceleration. As a result, the objects
will be first up to the floor
$\begin{array}{ll}\text { d. .... } & \text { b. not sure } \\ \text { Belief choices: } & \\ \text { a. sure * } & \end{array}$

Students with scientific conception in a matter of Mis-1 select answer $\mathrm{C}$ with A reason and responded with a confident (*) and at Mis-2 Selecting a reason $\mathrm{C}$ and answer confidently (*). The answer provided is intentionally made in pairs so as to simplify the analysis to decide the misconception of students. The results showed that the error does not occur over an interpretation of a choice answers. Alleged researchers with proven circuit student answer options where couples tier-1 option A will choose the tier-2 option B; tier-1 option B will choose the tier-2 option $\mathrm{C}$ and Lastly, tier-1 option C will select the tier-2 option a. This combination also complies with the Mis2.

At first glance, there are two very popular forms of dominant i.e. Mis-1 and Mis-3. Misconception-1 (Mis.-1) is the most popular with the IE reached $82 \%$. On Mis-1, students believe that the result of the hand-throw style still works because the object that is thrown is still moving towards the top (the gravity while heading to the center of the Earth). They don't believe if there is a force of gravity acting on the object.

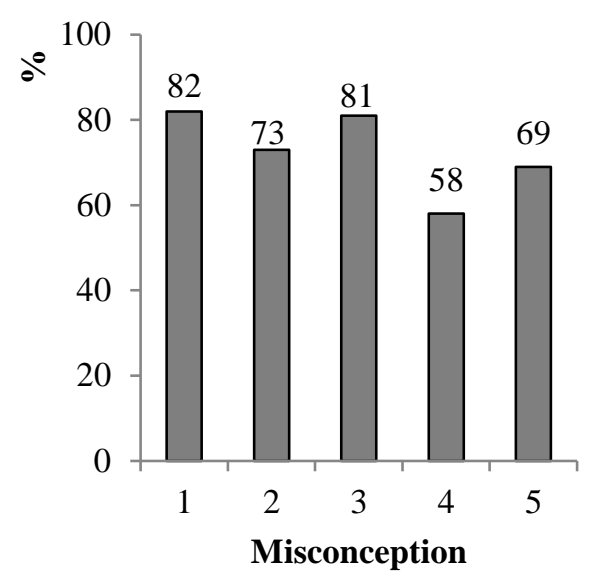

Figure 1. Distribution of Misconception in Newton II Law

The case is similar to the free fall of objects either by ignoring air friction or with taking into account the air friction. Only the forces acting on an object falling freely without air resistance is the force of gravity. On the contrary, taking into account air friction, then the falling objects (which originally had an acceleration $=$ acceleration of gravity) would be in equilibrium because it weighs offset by air friction (Halim, Yong, Subahan, \& Meerah, 2014)

Misconception 2 (Mis-2) is a common misconception to be experienced by high school students. They assume that the mass of an object affects the "speed" the free fall of a body. In fact, objects falling solely affected by gravity (assuming negligible air friction). If there is air, then the magnitude of the friction still hasn't been able to offset the force of gravity acting on the object (in terms of physics called weight).

Furthermore, Mis-3 percentage of $81 \%$ of the relationship style with speed. These assumptions are based on a table that moves (changing object position) resulting from given impulse (force). If the table is not encouraged (not styled) then objects (tables) are not moving. With 
that statement, they assume that force is proportional to velocity. This means that no matter how the conditions of the motion of objects (vertical or horizontal), as long as the resultant force applied to the object's value are fixed then the object also definitely moves with constant velocity (Resbiantoro \& Nugraha, 2017).

This is a fallacy because the concept of the truth is emerging due to the acceleration of the forces acting on an object. With the advent of the acceleration means that the objects are not in equilibrium so that the resultant force $\sum \vec{F} \neq 0$, moving objects (switch position). Objects will tend to grow quickly if direction $=$ direction of the total style of motion of objects.

For the smallest percentage with a misconception to $58 \%$ is Mis-4. It discusses the misconception about friction and its application. Students assume that objects (the surface) rough certainly have great friction and smooth surface objects such as glass do not have friction. This assumption is incorrect, because on the very fine objects though still there is friction between particles due to the contact between the dots surface bolt (Nave, 2018)

The interesting thing was found because of the alleged outside researchers is the high percentage of mis-5. On Mis-5, researchers deliberately tried to interfere with the cognitive of the students by providing a simple demonstration by throwing objects onto the top. Students believe that the direction of the force on an object that was thrown by the hand of investigators is headed to the top so closely with the movement of objects. Overthinking like that, the students concluded that the direction of motion of the object is always the same as the direction of the force acting on it.
Scientifically, the objects that are moving up to the top, will experience the gravitational influence of the Earth. In other words, the force acting on the object while the object is being moved up is the force of gravity (Earth). The direction of motion of the object is headed to the top while the force of gravity (Earth) to the center of the earth so the two opposites. This fact also indicates that the direction of speed is not always the same as the direction of the acceleration.

Researchers assume 5-Mis topics are familiar but the results of the analysis show that there are still many students who have the misconception (69\%). Although the Handbook of teachers and students have been discussing this subject matter, students still hold the conception originally so there happen incorrect conceptions of change became the scientific conception.

The tendency of students to defend the misconception caused (one of them) because the students refused to believe what he had seen and blame the procedure experimental/demonstration/phenomenon has done (Kurniawan, Suhandi, \& Hasanah, 2016).

As is known, the process of experimentation was certainly involving the observation process of the data and the experiments process. That is, the ability to observe the experiment/trial became a major point in acquiring learning experience. In addition, a failure to an identification of variables that are "served" during the ongoing phenomenon will certainly affect the results that will be reported. Errors-errors will also have an impact on errors in analyzing (interpret) data so that also promoted the understanding concept is supposed to be controlled (Muliyani, Kurniawan, \& Sandra, 2017).

Based on the results of data analysis, there are two categories namely, 
high and medium (table 4). The results of this research would certainly be jobs for all educators to address misconceptions.

Tabel 4. Criteria of Misconception

\begin{tabular}{ll}
\hline Misconseption & Criteria \\
\hline Mis-1 & High \\
Mis-2 & High \\
Mis-3 & High \\
Mis-4 & Medium \\
Mis-5 & Medium \\
\hline
\end{tabular}

Based on the data of table 4, there is no subject that has a small misconception (low). This means that the entire students have misconceptions on Newton law.

Resbiantoro \& Nugraha (2017) have researched and found some causes that can make students have misconceptions are: 1) the results of the internal thinking learners as much as $39 \%$; 2) experience observing events in everyday environments (daily events) as much as 38\%. 3) interpretation of the concept of teachers who delivered when the learning process of $19 \%$. 3) textbook $4 \%$.

The high percentage of the cause of the misconception comes from the personal experiences of the learners in observing the everyday phenomenon. This indicates that a misconception indeed can be affected by the daily experience. These results are in accordance with the statement of researchers in the analysis of the students asked back orally after known have all the misconception (Mis-1 until Mis-5)

\section{Conclusions and Suggestions}

Based on the analysis results and discussion, then it can be concluded that the level of misconception shared by students of SMP Negeri Pandeglang is at the high and medium category. On the study also found a misconception on Newton's Law II so that it becomes the basis for researchers to fix this problem. With the findings of the data that shows the high percentage of the misconception that is owned by the student, then the next researchers need to think of an appropriate teaching technique to correct the misconception, especially at the law of Newton and other physics concepts General.

\section{Reference}

Fadaei, A. S., \& Mora, C. (2015). An Investigation About Misconceptions in Force and Motion in High School. US-China Education Review, 5(1), 38-45. https://doi.org/10.17265/2161623X/2015.01.004

Halim, L., Yong, T. K., Subahan, T., \& Meerah, M. (2014a). Overcoming Students' Misconceptions on Forces in Equilibrium: An Action Research Study. Creative Education, 5, 1032-1042. https://doi.org/10.4236/ce.2014.511 117

Kurniawan, Y., \& Suhandi, A. (2015).

The Three Tier-Test for Identification the Quantity of Students' Misconception on Newton's First Laws. In GTAR2015 (Vol. 2, pp. 531-537). Retrieved from www.globalilluminators.org Kurniawan, Y., Suhandi, A., \& Hasanah, L. (2016). The influence of implementation of interactive lecture demonstrations (ILD) conceptual change oriented toward the decreasing of the quantity students that misconception on the Newton's first law. In AIP 
Conference Proceedings (Vol. 1708, pp. 70007-1-070007-5). https://doi.org/10.1063/1.4941180

Muliyani, R., \& Kaniawati, I. (2015). Identification of Quantity Students' Misconceptions on Hydrostatic Pressure with Three Tier-Test. In Global Trends in Academic

Research (Vol. 2, pp. 716-721). Retrieved from www.globalilluminators.org

Muliyani, R., Kurniawan, Y., \& Sandra, D. A. (2017). Peningkatan

Keterampilan Proses Sains Terpadu Siswa melalui Implementasi Levels of Inquiry ( LoI ). Tadris: Jurnal Keguruan Dan Ilmu Tarbiyah, 2(2), 81-86. https://doi.org/10.24042/tadris.v2i2. 1904

Nave, C. R. (Rod). (n.d.). Force.

Retrieved March 8, 2018, from http://hyperphysics.phyastr.gsu.edu/hbase/frict.html\#rou Resbiantoro, G., \& Nugraha, A. W. (2017). MISKONSEPSI MAHASISWA PADA KONSEP DASAR GAYA DAN GERAK UNTUK SEKOLAH DASAR. Jurnal Pendidikan Sains (JPS), 5(2), 80-87. Retrieved from http://jurnal.unimus.ac.id/index.php /JPKIMIA

Samsudin, A., Liliawati, W., Dedy, A., Suhendi, E., \& Kaniawati, I. (2014). The Use of Computer Simulation in Cooperative Learning to Minimize Students' Misconceptions of Momentum and Impulse. In International Conference on Advances in Education Technology (pp. 72-74). Atlantis Press. https://doi.org/10.2991/icaet14.2014.16 